\title{
HISTORICAL PHOTOS
}

To the young scientist, the publications of Vilhelm Bjerknes, Jaco6 Bjerknes, Tor Bergeron, ErikPalmén, Carl-GustafRossby, July Charney, Eric Eady, Arnt Eliassen, Ernst Kleinschmidt, Edward Lorenz, and Joseph Smagorinsky provide a fistorical perspective of some of the fundamentalcontributions to the advancement of atmospheric science. $\mathcal{T}_{0}$ the not-so-young scientist, revisiting these manuscripts is of ten accompanied by the remembrance of faces and times past, and the camaraderie with colleagues from fone and abroad that spans a professional lifetime. Our scientific heritage encompasses not only intellectual accounts and practical applications but also humanistic qualities of the individuals who gave rise to the contributions - a family heritage recounted through the telling of stories, often inspired by photographs in an album, a gathering of friends. This photographic essay was prepared as a visualization of some of our colleagues who have contributed to the advancement of our science and to the enrichment of our lives and of humanity.

The photographs presented herein were generously provided by $\mathcal{M} r s$. Jacob (Hedvig) Bjerknes, Arnt Eliassen, Jofn Green, Chester Newton, Hans Volkert, Robert Bundgaard, John Lewis, David Stuart, Akira Kasahara, the Norwegian Meteorological Institute, the University of Bergen, National Center for Atmospheric Research (NCAR), and the Royal Meteorological Society. We are especially indebted to NCAR Photographics for the extensive processing and printing of these photographs.

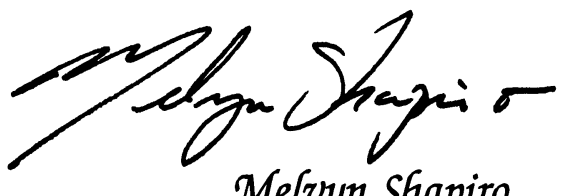

Melvyn Shapiro 